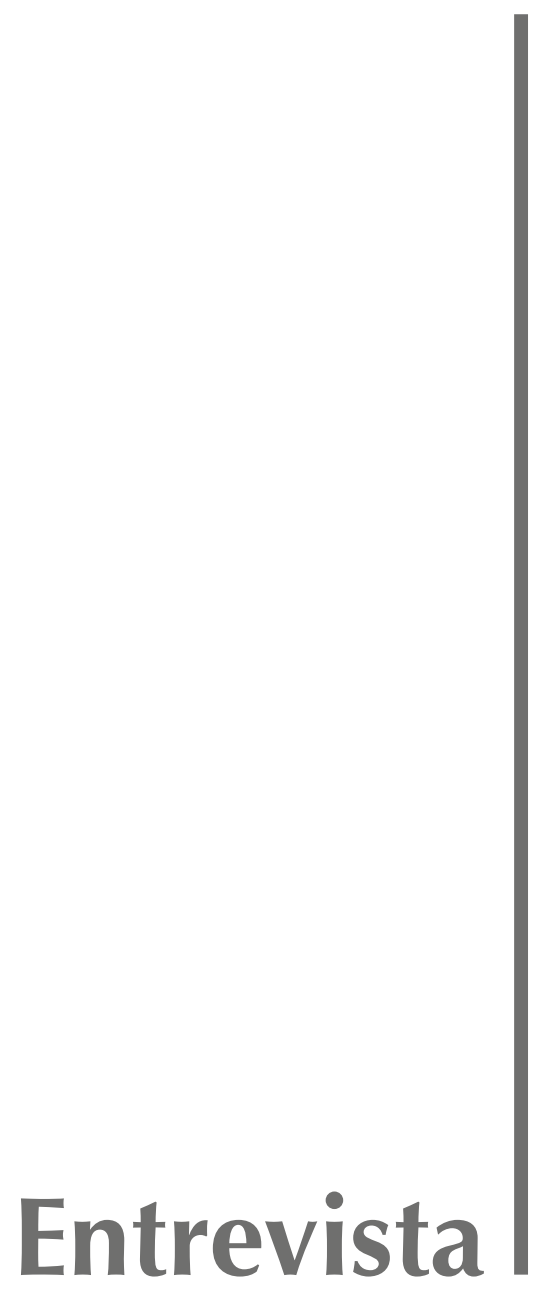





\title{
Entrevista a Wolfgang Kaleck: "Garantizar y proteger los derechos humanos con mecanismos jurídicos"
}

\author{
Por Claudia Cárdenas Aravena*
}

\begin{abstract}
Claudia Cárdenas es abogada, Licenciada en Ciencias Jurídicas y Sociales de la Universidad de Chile (1999), Magíster en Derecho por la Universidad Humboldt (Berlín, 2002) y Doctora en Derecho por la misma Universidad (2005). Dedica su quehacer académico especialmente al derecho penal internacional, el derecho penal transnacional y la justicia transicional. Desde 2008 se desempeña en la Facultad de Derecho de la Universidad de Chile. Actualmente es Profesora Asociada del Departamento de Ciencias Penales y Directora del Centro de Derechos Humanos de dicha Facultad.
\end{abstract}

\begin{abstract}
Wolfgang Kaleck es abogado de derechos humanos. En 2007 fundó, junto a otros abogados el European Center for Constitutional and Human Rights (ECCHR) en Berlín, y ha sido su Secretario General desde su establecimiento. Desde 1998 es abogado de la Coalición contra la Impunidad que lucha para condenar a oficiales del ejército argentino, responsables de la desaparición de ciudadanos alemanes durante la dictadura en dicho país. Entre 2004 y 2008 trabajó con el New York Center for Constitutional Rights (CCR) para seguir acciones legales contra miembros del personal militar norteamericano, incluyendo al ex-Secretario de Defensa, Donald Rumsfeld. Además es miembro del Centre of European Law and Politics en la Universidad de Bremen (ZERP), el Forum for International and Criminal and Humanitarian Law (FILCH), el Colectivo de Abogados José Alvear Restrepo en Colombia, y de la ONG mexicana ProDESC. Ha dictado múltiples conferencias, recientemente en América Latina, India, China y las Filipinas. Cuenta con diversas publicaciones en el área, entre las que se cuentan sus libros: Fighting against Impunity: Argentina's Military on Trial. Berlín, Klaus Wagenbach, 2010; Double Standards: International Criminal Law and the West. Bruselas, Torkel Opsahl Academic EPublisher, traducción al inglés de 2015 y Mit Recht gegen die Macht, Munich, Hanser Berlin 2015.
\end{abstract}

Como reconocimiento de su "compromiso tenaz e intrépido con las víctimas de violencia estatal y no estatal" fue galardonado en 2014 con el Premio Hermann Kesten (Hermann-Kesten-Preis) -otorgado por esfuerzos destacables en el apoyo a escritores perseguidos- en nombre del German PEN Centre, filial alemana de la asociación mundial de escritores.

\section{Introducción}

El quehacer de la sociedad civil sigue siendo un motor impulsor de cambios sociales y jurídicos, particularmente en materia de reconocimiento de los derechos de las personas y en su garantía. También cumple un rol relevante en dar vida a instrumentos y herramientas jurídicas previstos de distintos sistemas jurídicos, intentando o agotando las vías jurídicas disponibles para la protección y garantía de derechos y explorando nuevas vías, comprobando hasta dónde los recursos disponibles en los sistemas jurídicos son efectivos y planteando nuevos desafíos a dichos sistemas, o desafíos clásicos de formas novedosas.

En materia de derechos humanos, la sociedad civil ha sido fundamental en cuanto ha asumido el trabajoso rol de intentar nuevas vías y soluciones jurídicas para la efectiva garantía de los derechos, y la efectiva sanción de los responsables de sus vulneraciones graves, aun a sabiendas de que el camino al éxito en esos ámbitos suele ser largo y pedregoso. Claves como la acción en

\footnotetext{
* Entrevista traducida del alemán por Claudia Cárdenas Aravena.
} 
red y el litigio estratégico que hoy se miran como algo evidente han llegado a serlo por el trabajo permanente de la sociedad civil, ya sea organizada en ONG o por medio de abogados particulares.

El jurista entrevistado a continuación es un representante de esa sociedad civil organizada y alerta, que trabaja tanto representando directamente a mandantes como en su rol al frente del European Center for Constitutional and Human Rights (ECCHR), una organización independiente dedicada al litigio estratégico, que inicia, desarrolla y apoya procedimientos judiciales como mecanismo para responsabilizar a los Estados y a otros actores no estatales por violaciones de los derechos humanos, concentrando su quehacer en tres áreas: crímenes internacionales y responsabilidad jurídica; empresas y derechos humanos; y género y derechos humanos.

Actualmente el trabajo del ECCHR abarca, entre otros, los siguientes asuntos: i) las violaciones graves de los derechos humanos en la lucha contra el terrorismo de Estados Unidos, Reino Unido y sus aliados en los centros de detención de Guantánamo, Irak y Afganistán, así como los ataques con aviones no tripulados; ii) los crímenes de guerra y la violencia sexual en Sri Lanka; iii) las violaciones graves de los derechos humanos, en Egipto, Bahrein, Siria, Uzbekistán, Chechenia, Filipinas y la República Democrática del Congo; iv) el esclarecimiento de los crímenes de las dictaduras en Argentina y Chile (Colonia Dignidad); y v) la responsabilidad de la OTAN y de la ONU en Serbia y Afganistán; vi) la contaminación del agua y problemas de salud causados en la zona cercana a la mina de cobre Tintaya-Antapacca vinculada a la empresa suiza Glencore; y vii) la violencia sexual en Colombia, habiendo presentado al respecto una denuncia junto a otras organizaciones no gubernamentales ante la Corte Penal Internacional.

En esta entrevista, Wolfgang Kaleck se refiere a los principales temas de la agenda de derechos humanos de 2014 y explica algunos aspectos de la labor del Centro que encabeza, refiriéndose en particular su vinculación con la academia y las artes; además de su trabajo en y para América Latina.

\section{Claudia Cárdenas: Desde tu rol de Secretario General del European Center for Constitutional and Human Rights, ¿cuáles fueron, en tu opinión, los principales temas de la agenda de derechos humanos durante el 2014?}

Wolfgang Kaleck: Los temas de derechos humanos más importantes en este momento son, para mí, las violaciones permanentes y estructurales de los derechos económicos y sociales de gran parte de la población mundial. Millones de personas en el sur global no tienen acceso suficiente a alimento y agua, ni acceso a una vivienda y educación dignas, ni tampoco un trabajo digno.

Además de esas violaciones estructurales de derechos humanos, que alcanzan a millones de personas, está por supuesto la alarmante violencia permanente de los conflictos desde el norte de África hasta el Oriente Próximo, Irak, Irán hasta Paquistán.

\section{Claudia Cárdenas: La institución que fundaste y diriges se ocupa de poner en práctica los recursos jurídicos para la protección de derechos humanos. ¿Por qué eligieron esa aproximación, entre las diversas posibilidades disponibles?}

Wolfgang Kaleck: La respuesta es simple: yo soy un jurista y he trabajado por años como abogado. Por eso me resulta natural valerme de medios jurídicos. Sobre la base de la experiencia de los últimos 15 años pienso, también, que los medios jurídicos pueden ser de utilidad en la solución de problemas de derechos humanos. Por supuesto, los procedimientos jurídicos siempre deben ser contextualizados, y en particular los problemas de derechos humanos de carácter estructural, 
como los que mencioné antes, solamente pueden ser resueltos por medios políticos y sociales. Sin perjuicio de eso, pienso que es importante enfrentarlos también desde una perspectiva jurídica.

\section{Claudia Cárdenas: ¿Con qué criterios seleccionan los casos de los que se van a ocupar como ECCHR?}

Wolfgang Kaleck: Esa es una pregunta muy difícil, porque nuestro concepto de llevar adelante procesos de derechos humanos internacionalmente se apoya, como es natural, en que aquellos que combatimos con los medios del derecho sean alcanzables por esos medios jurídicos. Eso lleva a que regímenes cerrados, como el de Corea del Norte, donde ocurren las violaciones de derechos humanos más horribles no son aptos para nuestro trabajo.

Además, nuestro trabajo depende fuertemente de cuestiones prácticas, como la cooperación con juristas locales, la posibilidad de disponer de recursos, la existencia de medios de prueba, etcétera. Todas estas son cuestiones que los juristas no suelen tomar muy en serio.

Claudia Cárdenas: Dentro del quehacer del ECCHR, un punto importante es el trabajo conjunto con universidades. ¿Cómo sirve al trabajo de abogados esta vinculación con la academia?

Wolfgang Kaleck: El trabajo conjunto entre abogados litigantes y universidades es de enorme importancia por dos razones: en primer lugar, nosotros trabajamos con recursos sumamente escasos, mientras que en las universidades está disponible una gran pericia en materia de derecho y de derechos humanos. El apoyo de las universidades es desde ese punto de vista importante para el éxito de nuestro trabajo. También se nos presenta reiteradamente la necesidad de analizar nuestra práctica y el trabajo en casos jurídicos específicos desde una perspectiva teórica. En esto las universidades pueden ser de gran ayuda.

En segundo lugar, ya que en muchas universidades, tanto en Europa como en América Latina, la formación está bastante alejada de la praxis y los derechos humanos no juegan un rol significativo, por ejemplo, en la formación universitaria alemana, es muy importante, que juristas jóvenes obtengan impulsos de abogados de derechos humanos desde la práctica.

Claudia Cárdenas: El ECCHR se caracteriza por tener contacto también con artistas y apoyar su trabajo. ¿Por qué han considerado relevante mantener ese como un rasgo distintivo?

Wolfgang Kaleck: El derecho no puede ser la única reacción a las violaciones de derechos humanos, sino, en todo caso, solamente puede colaborar en la solución de los problemas de derechos humanos. Por eso, para nosotros el trabajo interdisciplinario es de la más alta importancia. Como parte de ello nos es grato trabajar también con artistas, que tienen la capacidad de entablar y transmitir una conexión muy particular hacia el individuo y la sociedad.

Claudia Cárdenas: EI ECCHR se caracteriza por actuar internacionalmente, en conjunto con juristas de distintos países e incluso de distintos continentes. ¿Cómo es que esa forma de operar enriquece, en tu opinión, el trabajo a favor de los derechos humanos?

Wolfgang Kaleck: Vivimos en un mundo globalizado. Muchos de los grandes problemas, desde la crisis de la alimentación mundial, pasando por la contaminación ambiental y las violaciones de derechos humanos afectan todo el mundo. Sus consecuencias, como por ejemplo, las migraciones masivas, nos conciernen a todos. 
Muchos de aquellos a los que perseguimos a causa de las violaciones de los derechos humanos que cometen, actores estatales y empresas transnacionales, actúan internacionalmente. Por eso me parece incuestionable que también nosotros debemos actuar globalmente.

Claudia Cárdenas: El ámbito más asentado de acción del ECCHR es el ligado a la responsabilidad penal internacional en situaciones de violaciones masivas y sistemáticas de los derechos humanos. ¿Cuáles son las principales razones de que sea todavía tan difícil, en la práctica, lograr el castigo penal en esas situaciones? A partir de tu experiencia, ipuedes identificar factores comunes?

Wolfgang Kaleck: Tal como sucede con el derecho en general, también el derecho penal es solamente una de las posibles formas de reacción ante violaciones masivas de derechos humanos.

Por una parte es problemático, porque individualiza un injusto que es sistemático. En todo proceso penal debe tratarse la culpabilidad de personas individuales. Por otra parte, los sistemas de injusto solamente pueden funcionar si personas individuales participan de él.

Para nosotros es particularmente importante que no solamente se persiga a los que se limitaron a seguir una cierta política, como soldados y policías que tienen las manos manchadas de sangre, sino que la justicia penal internacional debe ocuparse de los que cargan con la principal responsabilidad: los miembros de gobierno, los generales y en parte también las empresas transnacionales.

Claudia Cárdenas: El ECCHR ha actuado en repetidas ocasiones contra las así denominadas medidas contra el terrorismo, que en definitiva han redundado en violaciones de derechos. iPuede decirse -en tu opinión- que progresivamente hay una mayor conciencia de que esas medidas deben tener límites?

Wolfgang Kaleck: Lamentablemente, los Estados occidentales han cometido numerosas violaciones de los derechos humanos en la así llamada lucha contra el terrorismo desde el 11 de septiembre de 2001. En particular, se afectó la prohibición absoluta de tortura en la teoría y en la práctica, sobre todo por Estados Unidos.

Nosotros intentamos actuar en contra de esta tendencia mediante denuncias penales ante tribunales nacionales e internacionales. Así, sobre la base del principio de la jurisdicción universal, hemos interpuesto denuncias contra el ex-Ministro de Defensa de Estados Unidos, Donald Rumsfeld, lo mismo que contra otros arquitectos y personas envueltas en la planificación del sistema de tortura estadounidense en los años 2004 y 2006 en Alemania, en el año 2007 en Francia, en el año 2010 en España, en el año 2011 en Suiza y el año 2014 de nuevo en Alemania.

En enero de 2014 interpusimos una denuncia por tortura sistemática contra prisioneros de guerra en Irak ante la Corte Penal Internacional, imputando a militares y políticos británicos. Valoramos como un gran éxito el que la Fiscal de la Corte Penal Internacional haya decidido abrir un examen preliminar sobre esa base en mayo de 2014.

Claudia Cárdenas: ¿Cómo se compatibiliza, en tu opinión, la vigencia irrestricta de los derechos humanos con ciertos regímenes de excepción jurídica, como por es por ejemplo, un conflicto armado, donde rige el derecho internacional humanitario, que permite ciertas formas de daño a la población civil, mientras no sean desproporcionadas?

Wolfgang Kaleck: El derecho internacional humanitario debiera reformarse, de modo de proteger de mejor manera a la población civil durante los conflictos armados. En este momento, el derecho es demasiado permisivo. 
Claudia Cárdenas: Parece indesmentible que ciertos usos de las tecnologías actualmente disponibles afectan masivamente los derechos de las personas, al espiarlas masivamente. ¿Qué mecanismos de protección de los existentes hoy podrían ser idóneos para hacer frente a este fenómeno?

Wolfgang Kaleck: Las revelaciones de Edward Snowden nos demostraron que la NSA, parte del servicio secreto estadounidense, utiliza todas las posibilidades tecnológicas para monitorear individuos en todo el mundo. Quiero ser franco: No cabe duda alguna que eso no es solamente un problema vinculado al abuso de poder por parte de las autoridades estadounidenses, sino que la mayoría de los gobiernos recurriría a estos medios si pudiera o ya las está empleando. Y me parece que en este momento no existen medidas jurídicas y políticas eficaces para poder frenar y controlar este desarrollo.

Creo que la mejor resistencia a estas masivas violaciones de derechos humanos sería muy similar a aquella que intentamos de movilizar frente a otras violaciones: Le hace falta que se forme un fuerte movimiento social que demanda el fin de estas prácticas y que desarrolle la presión política necesaria para la realización de esta meta. El litigio estratégico que practica el ECCHR puede aportar su parte a tal movimiento, por medio de su capacidad de establecer formalmente las violaciones ocurridas y de escandalizarlas.

No obstante, esta categoría de violaciones de derechos humanos trae consigo retos específicos: Como las prácticas de las cuales hablamos están rodeadas de tanto secretismo, es difícil obtener el conocimiento y las pruebas necesarias para poder accionar jurídicamente. De esta característica también resulta que las poblaciones afectadas no sienten un efecto inmediato de la supervisión permanente. Por eso, mucha gente no siente la urgencia de protestar contra ella, aunque las violaciones subyacentes sean masivas. Espero que el paso que ha tomado Edward Snowden para informar el público haya sido el comienzo de una fuerte oposición a la vigilancia masiva.

\section{Claudia Cárdenas: ¿Qué rol cumple el ECCHR en América Latina?}

Wolfgang Kaleck: Para el ECCHR, la cooperación con partners de América Latina siempre ha tenido una importancia fundamental. Hemos trabajado en la persecución de crímenes cometidos durante las dictaduras militares en Chile y Argentina y del involucramiento de varias empresas en tales crímenes. También estamos cooperando con sindicatos y defensores de derechos humanos en Colombia, con la meta de obtener justicia por los crímenes sistemáticos que se están cometiendo, tanto contra sindicalistas como contra mujeres y la población civil en general, durante el conflicto armado colombiano.

Nuestro rol en la cooperación con colegas latinoamericanos es la facilitación de medidas difícilmente accesibles en los países mismos. En Argentina y Chile, por ejemplo, por mucho tiempo no había ninguna posibilidad de iniciar investigaciones de los crímenes acontecidos durante las dictaduras. Al mismo tiempo, había un movimiento por los derechos humanos muy fuerte que, en cooperación con aliados transnacionales como nosotros, intentaba todo lo posible para iniciar investigaciones y juicios fuera de los países mismos. Y de repente se detuvo a Pinochet en Inglaterra y poco después se abolió la ley de amnistía en Argentina. Creo que la presión desarrollada por la cooperación entre actores locales y transnacionales fue clave para estos éxitos.

Claudia Cárdenas: Una de las líneas de trabajo está descrita como "empresa y derechos humanos". ¿Qué relevancia ves que tiene o puede llegar a tener esa arista en América Latina?

Wolfgang Kaleck: Desde los procesos a los criminales de guerra en Núremberg y los procesos sucesivos al juicio de Núremberg contra las elites de la Alemania nazi, pertenece al sentido 
común jurídico que no solamente quienes trabajan en el Estado y los militares deben responder por crímenes contra el derecho internacional. También quienes manejan la economía ayudan de muchas formas a construir y a que operen sistemas injustos en que se cometen masivamente esa clase de crímenes, de los que ellos sacan provecho. Por eso es importante aplicar el derecho penal internacional también contra ellos.

Aun cuando el desarrollo del derecho penal internacional desde el establecimiento de la Corte Penal Internacional en el año 2002 es destacable, lo mismo que el éxito de diversos procesos nacionales, tanto basados en el principio de la jurisdicción universal como también en Estados territoriales, como lo muestran varios ejemplos en Argentina y en Chile; resulta asimismo importante, para las organizaciones de derechos humanos, ocuparse de los actores de la economía. Las violaciones de derechos humanos suelen tener causas políticas y económicas, que no deben quedar fuera del análisis político ni del trabajo jurídico. Esto vale tanto para América Latina como para el resto del mundo.

Claudia Cárdenas: Por tu trabajo, tienes contacto permanente con abogados de, por lo menos, Colombia, México, Argentina y Chile. ¿Puedes ver algún denominador común que sea al mismo tiempo un rasgo distintivo del trabajo en materia de derechos humanos desde los países latinoamericanos?

Wolfgang Kaleck: El desarrollo en materia de derechos humanos en la América Latina de los últimos 15 años es esperanzador. En la actualidad, en muchos Estados se Ilevan adelante procesos que tienen por objeto los grandes crímenes de las dictaduras y regímenes represivos de las décadas de 1970 y 1980 . Esto debe agradecerse sobre todo a los fuertes movimientos por los derechos humanos, pero también a los muchos juristas que han participado en estos procesos.

Para nuestro trabajo, América Latina juega un rol especial, porque los muchos casos relacionados con las dictaduras militares en Chile y Argentina y, en particular, la detención de Augusto Pinochet en octubre de 1998 en Londres dieron un impulso decisivo para el trabajo transnacional en materias de derechos humanos. 